\title{
Estimación de capacidad de carga comercial en las playas de San Lorenzo y Chipipe, Salinas
}

\section{Estimation of commercial carrying capacity in San Lorenzo and Chipipe beaches, Salinas}

\author{
Otto Suárez Rodríguez, Universidad Tecnológica Equinoccial, Sede Santa Elena (otto.suarez@ute.edu.ec) \\ Juan Ramos Peredo, Universidad Tecnológica Equinoccial, Sede Santa Elena (jaramos@ute.edu.ec) \\ Recibido: 2016-09-20Ａceptado: 2017-02-01
}

\begin{abstract}
Resumen
Las playas de San Lorenzo y Chipipe, las más concurridas del cantón Salinas, soportan durante las temporadas altas una fuerte carga de visitantes y de vendedores ambulantes. Para la autoridad local esta situación es un aspecto crítico de su gestión, puesto que en primer término el turista exige el pleno disfrute de su visita y luego el vendedor en ejercicio de su derecho al trabajo busca un espacio para realizar su actividad. En respuesta a ello, este estudio mide la capacidad de carga de vendedores ambulantes bajo diferentes escenarios y en el proceso se estiman las cargas reales de turistas que experimentan estas playas. Para el efecto, se determinan parámetros de medición de las áreas efectivas de uso turístico y el área promedio que ocupa cada turista y vendedor. Los resultados obtenidos constituyen una herramienta clave para la implementación de políticas de organización y control de los espacios públicos.
\end{abstract}

Palabras claves: capacidad de carga, turismo playero, vendedores ambulantes

\begin{abstract}
The beaches of San Lorenzo and Chipipe, the most visited of Salinas, support during high seasons a heavy load of visitors and mobile vendors. For local authorities this is one of the most critical issues to manage since on one band tourists demand ajoyful experience of theirvisit and on the other handvendors, exercising their right to work, demand adequate conditions to do it. In response to that, this study measures the carrying capacity of mobile vendors under different scenarios and in the process the real carrying capacity of tourists on these beaches is estimated. For this purpose, measurement parameters are determined for the effective area of tourist use and the average area occupied by each tourist and vendor. Resulting measurements become a key toolforpolicy making regarding the organization and control ofpublic spaces in tourist areas.
\end{abstract}

Keywords: carrying capacity, beach tourism, mobile vendors 


\section{INTRODUCCIÓN}

Ecuador es actualmente uno de los destinos turísticos más completos del mundo. Según cifras del Ministerio de Turismo del Ecuador, el turismo creció en el año 2014 a una tasa del $14,1 \%$ con respecto al año anterior. Esto es tres veces más que el resto del mundo, que en promedio crecióal 5\% (Ministerio de Turismo, 2015).

Entre los principales destinos turísticos del Ecuador están las islas Galápagos, Quito, la ruta de los volcanes, Guayaquil, Cuenca y la reactivada ruta del tren Durán - Quito. Las playas del Ecuador constituyen un importante imán para los turistas extranjeros, especialmente de Colombia y Perú, pero en particular atraen a los turistas nacionales, que se vuelcan a las playas durante los largos feriados de fin de año, Carnaval y Semana Santa.

La provincia de Santa Elena, privilegiada por la gran cantidad de atractivos naturales, destaca por sus playas tales como Montañita, Olón, Ballenita y las reconocidas playas del cantón Salinas: San Lorenzo y Chipipe, que por su ubicación y bondades naturales atraen masivamente a los turistas.

Sin embargo, la creciente popularidad de Salinas como destino turístico ha significado un impacto cada vez mayor sobre sus playas y la infraestructura turística en general, y sobre todo en los feriados nacionales, la afluencia de visitantes tiende a exceder la capacidad de carga que puede soportar la infraestructura turística, en alojamiento, alimentación, transporte, servicios básicos y las mismas playas, lo cual genera un sinnúmero de problemas para los visitantes y residentes del cantón, así como para las autoridades competentes.

No obstante lo anterior, esta gran afluencia turística es positiva para la economía del cantón, pues se genera empleo y se incrementan los ingresos de sus habitantes y del resto de la provincia, incluyendo a los comerciantes de las playas que ven aumentada su liquidez durante estos días.

El problema radica en que así como se incrementa la afluencia de visitantes también se incrementa la presencia de vendedores. A pesar de la existencia de la Ordenanza que regula las actividades comerciales en las playas (Gobierno Autónomo Descentralizado del cantón Salinas, 2013), la aplicación de las normativas ha tenido para la autoridad competente algunas dificultades en el control del número de vendedores ambulantes, especialmente durante la temporada alta, lo cual incrementa significativamente la densidad de vendedores en las áreas de playa causando malestar al turista. Esta situación tiende a ser más crítica en las playas de San Lorenzo y Chipipe, objetos de este estudio.

Ante tal situación, este estudio busca medir la capacidad de carga comercial con relación a la superficie de playa disponible y la cantidad de turistas que en un momento dado acuden a las playas, para lo cual se establecen determinados parámetros de medición bajo diversos escenarios, todo esto en el marco de las normativas vigentes establecidas por el Gobierno Autónomo Descentralizado del Cantón Salinas - GADSA, como autoridad competente.

Al no existir parámetros que permitan evaluar de una forma objetiva y sistemática la densidad de uso de las áreas de playas por parte de turistas y vendedores, la autoridad competente no dispone de una herramienta fundamental de planificación territorial. Al ser el fin último el bienestar de los visitantes debe procurarse permanentemente una interacción equilibrada y armónica con los vendedores, para que los unos disfruten su experiencia recreativa y los otros ejerzan su actividad comercial dentro de la normativa establecida.

\section{CARACTERIZACIÓN Y DESARROLLO TURÍSTICO DE SALINAS}

Salinas, cabecera cantonal del cantón del mismo nombre, es una ciudad balneario ubicada en la punta más saliente del perfil costanero del Ecuador, conocida como punta de Santa Elena. Dispone de dos playas que están entre las más concurridas del país: San Lorenzo y Chipipe.

\section{Figura 1. Mapa de Salinas}

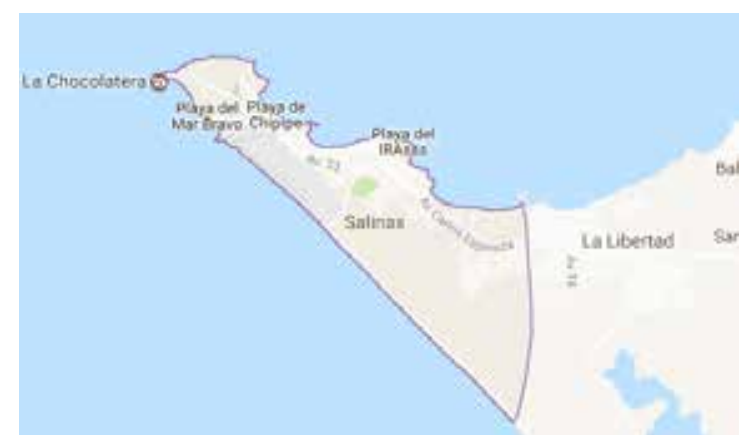

Fuente: Google (2015)

Hasta fines del sigloXIX, lo que es actualmente Salinas era básicamente un poblado de pescadores. Ya en los albores del siglo XX, se avizoraba el potencial turístico de Salinas por su clima, su mar apacible y la cercanía a la ciudad de Guayaquil. Con la construcción de un ferrocarril y posteriormente de 
una vía carrozable que unía Salinas con Guayaquil, cada vez era mayor la afluencia de visitantes.

Para mediados de siglo ya estaba institucionalizada la temporada playera para los guayaquileños que hasta el día de hoy se conoce como temporada alta y que coincide con el período vacacional de los estudiantes de la costa entre enero y abril de cada año.

De ahí en adelante, Salinas poco a poco fue ganando el sitial que aún ostenta como primer balneario turístico del Ecuador. Con el boom petrolero de los años 70, empezó un proceso acelerado de urbanización con grandes edificaciones, propiedades horizontales, ciudadelas, hoteles de buena calidad y desarrollo de infraestructura en general.

Esto sumado a la presencia creciente de turistas de la Sierra durante la temporada vacacional de los escolares de esa región desde junio hasta agosto de cada año, así como la tradición ya establecida como visita obligada para despedir el año que atrae gran cantidad de turistas en diciembre de cada año y por último la apertura en el 2014 del aeropuerto "Ulpiano Páez" de Salinas para rutas comerciales como la que actualmente existe entre Salinas y Quito, han hecho de Salinas ya no solo un destino de temporada alta sino permanente.

\section{CARACTERIZACIÓN DE LAS PLAYAS DE SAN LORENZO Y CHIPIPE}

Las playas de San Lorenzo y Chipipe son las dos playas urbanas más concurridas y tradicionales de Salinas, separadas por el espigón del Yacht Club y con características quelas hacen marcadamente diferentes. La playa de San Lorenzo (Figura 2) se extiende desde el Yacht Club hacia el sureste con una curva en el sector denominado "Las Palmeras" donde la playa se presenta más ancha y con una gran cantidad de arena suelta. Aproximadamente a partir de la calle "24 de Mayo" 21A, la playa se hace más recta pero al mismo tiempo más estrecha, al punto que a medida que se extiende hacia el este, en ciertos sectores tiende a desaparecer con marea alta (Ministerio del Ambiente, 2009). Esta playa se extiende aproximadamente hasta la altura del hotel Barceló. La extensión de la playa desde el sector Las Palmeras hasta el hotel Barceló es de aproximadamente 1.284 metros, pero en sí el área de uso turístico se extiende solamente hasta el muelle frente a la Capitanía del Puerto, con un total de 944 metros de largo aproximadamente. Los anchos fluctúan desde unos 117 metros en el sector de Las Palmeras decreciendo progresivamente hasta unos
15 metros en el sector del muelle. Cabe indicar que el ancho se considera desde el inicio de la arena hasta aproximadamente la línea de marea diaria promedio.

Figura 2. Playa de San Lorenzo, Salinas

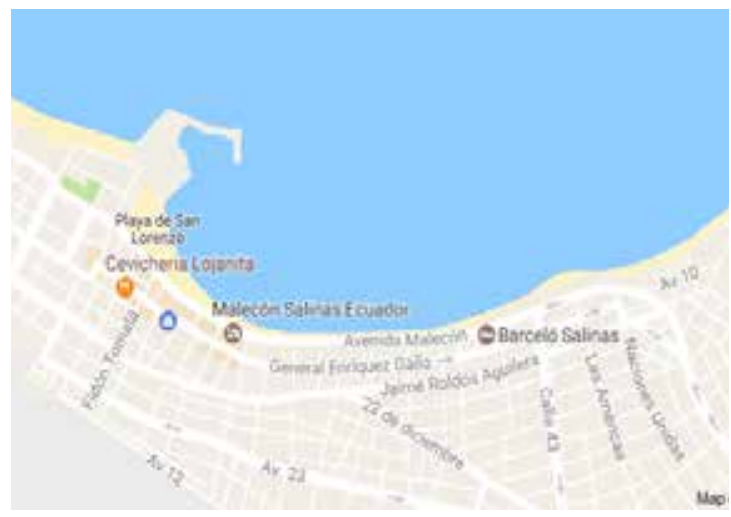

Fuente: Prefectura de Santa Elena

La playa de Chipipe (Figura 3) es recta a lo largo de toda su extensión y con un ancho uniforme y bastante amplio con una gran cantidad de arena suelta por donde acceden los turistas desde la calle del Malecón. Esta playa forma una especie de ensenada entre el "Yacht Club" al norte y el acantilado conocido como "La Chocolatera" al sur, lo cual hace que el oleaje en esta playa no sea muy fuerte (Ministerio del Ambiente, 2009).

El uso turístico de esta playa se extiende desde el "Yacht Club" hasta la calle 1 Atahualpa donde se inician las instalaciones de la Base Naval. Esta extensión útil es de aproximadamente 959 metros con un ancho promedio de unos 80 metros.

Figura 3. Playa de Chipipe, Salinas

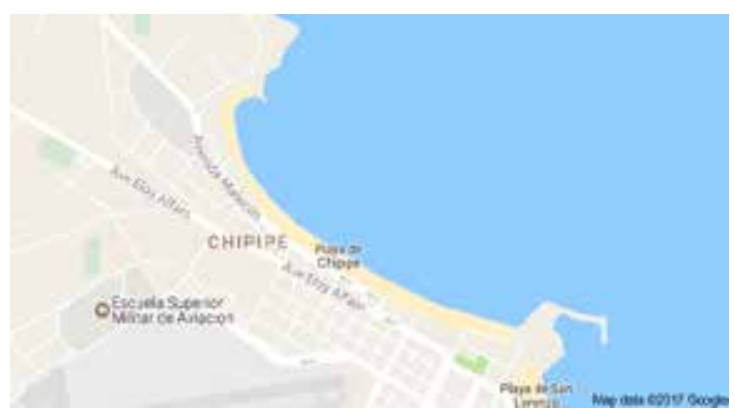

Fuente: Prefectura de Santa Elena

Las playas de San Lorenzo y Chipipe por ser las más concurridas atraen una cantidad considerable de vendedores ambulantes que, sobre todo en temporadaalta, ofertan unaampliagamade productos. LaventaambulanteenlasplayasdeSanLorenzoyChipipe 
Las playas de San Lorenzo y Chipipe por ser las más concurridas atraen una cantidad considerable de vendedores ambulantes que, sobre todo en temporadaalta, ofertan unaampliagamadeproductos.

LaventaambulanteenlasplayasdeSanLorenzoyChipipe Según Fioravanti et al. (2007), la venta ambulante en las playas tiene laventaja que los vendedores llevan sus productos y servicios directamente al turista mientras este disfruta de la playa. Desde la óptica económica, la venta ambulante es una de las principales fuentes de ingresos generados por el turismo playero. Sin embargo, los mismos autores señalan que la venta ambulante tiene sus aspectos negativos, tales como:

- Generación de desechos orgánicos e inorgánicos en las playas.

- Exceso de vendedores ambulantes que perjudica la tranquilidad del turista.

- Gran cantidad de vendedores "flotantes", es decir ajenos a la comunidad, que solo acuden en feriados y no colaboran con el aseo y el orden de la playa.

Por tales motivos, esta actividad comercial debe ser regulada; sin embargo, es una actividad que se sale fácilmente de control sobre todo en feriados importantes, por la extensión de las playas y la cantidad considerable de gente que acude a ellas.

En general, las normativas buscan mantener una cantidad adecuada de vendedores en las playas y que solo estén aquellos calificados por la autoridad para ejercer su actividad y participar en el mantenimiento, aseo y orden de las playas.

La venta ambulante en las playas de San Lorenzo y Chipipe se encuentra normada por una Ordenanza (GADSA, 2013), que establece 17 asociaciones con vida jurídica y patente municipal para operar legalmente en las playas. De estas asociaciones, 12 son las que realizan su actividad en las playas del estudio y cuentan con un total de 750 comerciantes, de los cuales 582 son vendedores ambulantes y 168 se dedican al alquiler de carpas y parasoles. Conforme la normativa, cada socio es un vendedor que se dedica solamente a una sola actividad.

Los vendedores ambulantes en su mayoría ofrecen bebidas y productos alimenticios ligeros, otros se dedican a la venta de ropa, artesanías, a hacer trenzas y tatuajes, entre otras actividades. Por su naturaleza, el alquiler de carpas y parasoles son actividades comerciales fijas. La ordenanza limita el número de carpas y parasoles que puede instalar cada socio que se dedica a esta actividad, según esta distribución: SanLorenzo: 2 carpasy 2 parasolesalinicio, 4 y6máximo. Chipipe: 2 carpas y 2 parasoles al inicio, 10 y 6 máximo.

La Ordenanza establece que las actividades de venta, sean estas fijas o ambulantes, solo se realicen en las áreas designadas para estos fines. Además, la cantidad de vendedores permitidos para laborar en las playas del cantón se determina tomando en consideración un vendedor por cada diez turistas satisfechos.

Las playas de San Lorenzo y Chipipe por ser las más concurridas atraen una cantidad considerable de vendedores ambulantes que, sobre todo en temporadaalta, ofertan unaampliagamade productos.

\section{MATERIALES Y MÉTODOS}

\section{CAPACIDAD DE CARGA}

El concepto de capacidad de carga en sus orígenes fue aplicado a las ciencias pecuarias para el manejo eficiente de los pastizales (Ruschmann, Paolucci \& Maciel, 2008) y en las ciencias biológicas como una herramienta degestión delos espacios naturales. En el ámbito turístico fue desdelos años 70 cuando empezó a aplicarse con mayor frecuencia como una respuesta a la necesidad de gestionar los flujos de visitantes en espacios naturales protegidos (Antón et al.2005). En uno de los trabajos pioneros, Wagar (1964) dio tal vez la primera definición formal de capacidad de carga aplicada a la recreación como el nivel de uso de un área al cual su calidad no se ve afectada.

El geógrafo George definiólacapacidad de carga como "la tolerancia de cada punto del territorio para acoger los usos del suelo sin que se produzcan deterioros en el medio más allá de los límites tolerables" (García Menéndez citado por Navarro Jurado, 2005). Dada la naturaleza genérica de esta definición, los usos del suelo pueden ser múltiples y dentro de estos cabe el uso turístico. De modo que si aplicamos este concepto en las actividades turísticas la capacidad de carga se define como el "umbral de actividad turística más allá del cual se produce una saturación del equipamiento turístico, una saturación del medio ambiente o una disminución de la calidad de la experiencia turística" (Leno Cerro citado por Navarro Jurado, 2005). Esta definición como se puede ver incluye variables no solo de carácter físico y ecológico sino también social y psicológico al considerar el disfrute del visitante en su experiencia turística.

Tal acepción y la metodología correspondiente utilizada para su cálculo, ha tenido un uso 
generalizado desde los años 90 en una gran cantidad de estudios, sobre todo a partir del trabajo seminal de Cifuentes (1992) que considera tres tipos de capacidad de carga: capacidad de carga física (CCF), capacidad de carga real (CCR) y capacidad de carga efectiva (CCE).

El primero establece una simple relación entre el espacio disponibley el espacio normal que ocupacada visitante; el segundo ajusta el primero sometiéndolo a una serie de factores de corrección que hacen cuenta de las características biofísicas del sitio, así como aspectosambientales, ecológicosysociales; finalmente la CCE da cuenta de los aspectos administrativos que permiten un manejo adecuado del área.

La definición relevante y en consecuencia la metodología a aplicar para un estudio en particular está en función del objeto de la investigación que permita delimitar elámbito de aplicación conceptual.

Para el presente estudio se justifica aplicar la capacidad de carga física puesto que lo que interesa es estimar el número de usuarios y en consecuencia el número de vendedores dada el área disponible en las playas de estudio.

Hay que tomar en cuenta también que la metodología planteada por Cifuentes tiene aplicabilidad en áreas protegidas donde los aspectos ambientales y ecológicos de conservación del sitio son más críticos comparados con una playa pública.

EnlaformulacióndelaCCF, Cifuentesincluyólavariable tiempo de visita puesto que para áreas protegidas esta es una variable relevante que debe considerarse en el recorrido de senderos y otras áreas donde la rotación de visitantes y los ingresos controlados son herramientas clave de gestión, no así en el caso de las playas públicas donde estos elementos no son mayormente relevantes (Ruschmann et al., 2008).

De modo que la fórmula a aplicar en el presente estudio es la siguiente:

$$
\mathrm{CFF}=\frac{\mathbf{S}}{\mathrm{S}}
$$

donde $\mathbf{S}$ = superficie total del área efectiva de uso turístico y $\mathbf{S}=$ área ocupada por cada usuario

(Dias, Korossy \& Fragoso, 2012).

Esta fórmula da como resultado el número máximo de visitantes que puede contener una playa en un momento determinado.

\section{ÁREA EFECTIVA DE USO TURÍSTICO}

El área efectiva de uso turístico comprende aquel espacio de una playa donde la mayoría de la gente tiende a colocarse o hace base, esto es en carpas o parasoles, y parte del espacio disponible para actividades recreativas como caminatas, deportes, juegos, entre otros. Quedan descartadas por lo tanto las áreas de acceso ubicadas detrás de las carpas y parasoles y parte de las áreas de arena húmeda que sirven de acceso al mar.

La Figura 4 muestra un diagrama de una playa tipo donde se distinguen las diferentes zonas de uso de una playa. Se puede apreciar en este diagrama que del largo total de una playa se debe considerar solamente el largo efectivo, mientras que del ancho se debe tomar el ancho suficiente que incluya a las carpas y parasoles y parte de la playa húmeda más cercana a las carpas y parasoles. De manera que queda como área efectiva de uso turístico la zona delimitada por las líneas punteadas.

\section{La economía en la playa}

Una playa pública constituye un escenario adecuado para analizar la interacción de las fuerzas de la demanda y la oferta de mercado.

La demanda la componen los turistas que, además de demandar la recreación y el goce de una playa, son potenciales consumidores delos múltiples productos y servicios que se ofrecen y que complementan ese disfrute. En efecto, el turista playero, a diferencia de otros tipos de turistas, concibe la experiencia de la visita a la playa como un todo donde se conjugan tanto el disfrute de las recreaciones naturales que ésta ofrece, como el mar, la arena, las olas cuanto el consumo de productos y servicios que tienen el potencial de hacer de esta experiencia única y de relajación total. Sin embargo, muchos turistas llevan sus propios productos para su consumo, mientras que un número apreciable espera encontrar quienes los ofrezcan en el mismo sitio.

Además, la oferta la componen los comerciantes que ofrecen un sinnúmero de productos, sobre todo alimentos y bebidas, alquiler de carpas, servicios recreativos, entre otros.

En base a lo expuesto, la playa se puede definir como un territorio a orillas del mar donde un grupo de visitantes o turistas van en busca de recreación, ocio, deportes, comidas, bebidas y otras amenidades, mientras que otro grupo va a trabajar y a ejercer 
Figura 4. Diagrama de playa tipo con identificación de zonas de uso turístico

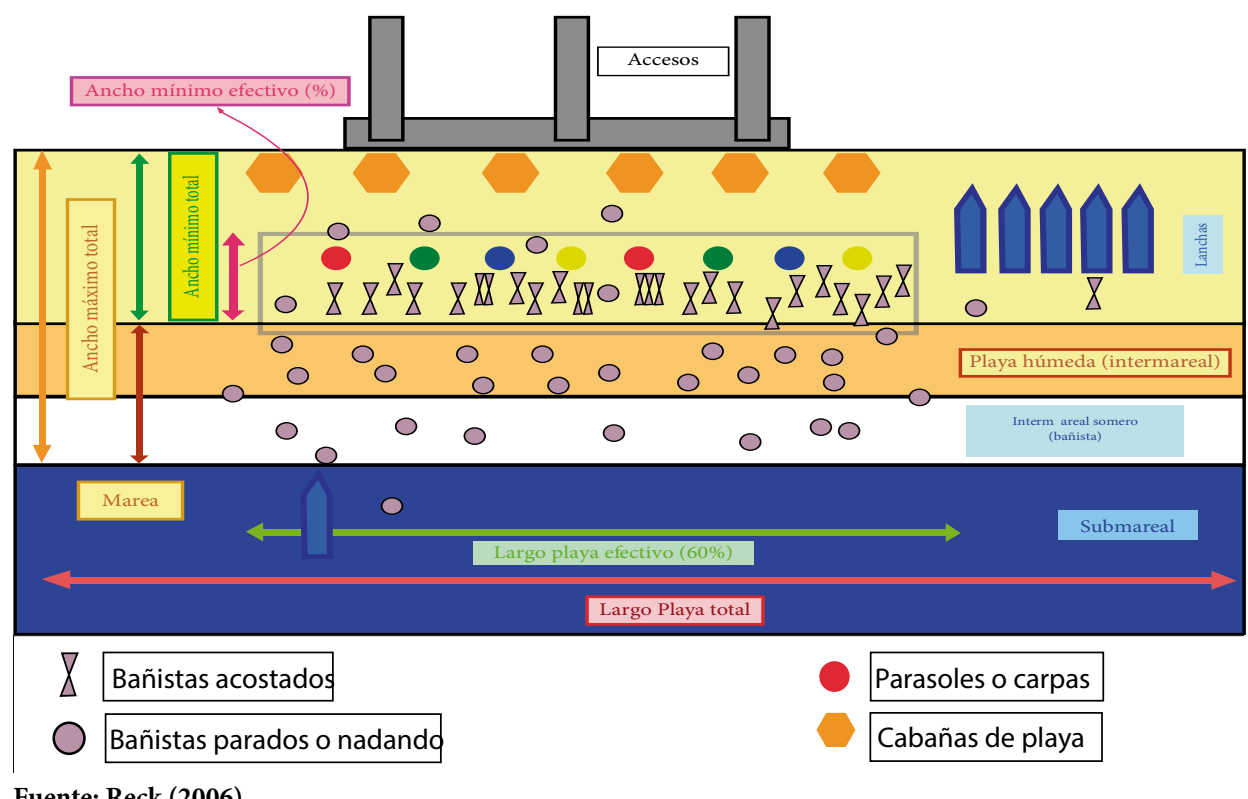

Fuente: Reck (2006)

actividades productivas que contribuyen a completar la experiencia del turista en forma satisfactoria (Loiola \&Miguezcitados por Novaes, Silva\& de Oliveira, 2010).

La interacción de ambos grupos delinea un mercado característico que se da en una playa pública, donde la oferta responde a la demanda con una dinámica que tiene pocos parangones en otros tipos de ambientes (Novaes, Silva \& de Oliveira, 2010).

En las playas objeto de estudio, precisamente se da esta situación, en que los vendedores fluyen a las playas en función de la cantidad de turistas; es así como en temporadas bajas son pocos los vendedores que se encuentran en las playas y los demás, para completar su presupuesto, deben dedicarse a otras actividades productivas o buscar otros mercados ${ }^{2}$. No así en el caso de temporadas altas, en que prácticamente todos los vendedores locales o afuereños, legalizados o no, se vuelcan a las playas ante la presencia abrumadora de turistas. Con este criterio, cualquier estimación de la capacidad de carga comercial debe necesariamente partir de la estimación de la capacidad de carga física de turistas utilizando la fórmula planteada.

\section{Proceso de estimación de la CCF}

Para estimar la capacidad de carga física, se necesita medir el área total de uso turístico y el área que en promedio utiliza un turista. Estas mediciones se hicieron durantefines de semana y a horas pico entre $11 \mathrm{~h} 00 \mathrm{y} 13 \mathrm{~h} 00$, en que haymayorafluenciadevisitantes.

\section{Cálculo de área usada por turistas}

Para el cálculo de estas áreas se utiliza el criterio que la mayoría de turistas hacen base en las carpas y parasoles para desde ahí dirigirse a nadar al mar, a practicar actividades recreativas, a jugar o simplemente yacer en la arena húmeda. La medición de la superficie de una playa tiene dificultades que emanan principalmente por la precisión con que se mida el ancho de la playa, pues éste se ve afectado por la línea de marea, no así la longitud que se puede medir sin mayor inconveniente. Es importante indicar que el ancho total de una playa va desde donde empieza la arena hasta donde llega la marea. En el caso de la playa de San Lorenzo, dada su forma geométrica irregular, se determinaron 8 áreas rectangulares para la medición. No se consideró el ancho correspondiente a la arena suelta de acceso sino desde donde inician las carpas hasta la línea de marea promedio.

Este ancho se dividió a su vez en dos anchuras: un ancho correspondiente a las carpas y parasoles y otro ancho correspondiente a la arena húmeda, identificado como playa húmeda en la Figura 4. El primer ancho sirvió para determinar el área efectiva de uso turístico que corresponde al área comercial fija de carpas y parasoles mientras que el otro ancho sirvió para determinar elárea de circulación comercial pues es por ella donde transitan los vendedores ambulantes. Sin embargo, dado que los vendedores notransitan a todoloanchode estaáreasino próximos 
a los parasoles y carpas donde están los turistas, se realizó un ajuste para únicamente considerar el área exclusiva de circulación de vendedores. En el cálculo del área comercial fija se descontó el área correspondiente a las rampas de acceso para vehículos de emergencia y motos acuáticas, botes y demás implementos de recreación deportiva. Así mismo se descontó el área que ocupan las torres salvavidas más el área enfrente de ellas que siempre debe permanecer despejada. Como se explicó anteriormente, la longitud efectiva de la playa de San Lorenzo dio una medida de 944 metros desde el sector "Las Palmeras" hasta el muelle de la Capitanía del Puerto. Los resultados de la medición de esta playa se presentan en la Tabla 1.

Tabla 1. Cálculo de áreas fijas y áreas de circulación en la playa de San Lorenzo

\begin{tabular}{|c|c|c|c|}
\hline \multicolumn{4}{|c|}{ Área Fija } \\
\hline Rectángulos & $\begin{array}{c}\text { Ancho } \\
\text { (m) }\end{array}$ & $\begin{array}{c}\text { Base } \\
(\mathrm{m})\end{array}$ & $\begin{array}{l}\text { Área } \\
\left(m^{2}\right)\end{array}$ \\
\hline Área 1 & 20,00 & 99,54 & $1.990,80$ \\
\hline Área 2 & 20,00 & 99,54 & $1.990,80$ \\
\hline Área 3 & 11,60 & 121,21 & $1.406,04$ \\
\hline Área 4 & 9,90 & 68,94 & 682,51 \\
\hline Área 5 & 9,90 & 13,37 & $1.122,36$ \\
\hline Área 6 & 6,20 & 86,09 & 533,76 \\
\hline Área 7 & 6,20 & 157,11 & 974,08 \\
\hline Área 8 & 6,20 & 198,00 & $1.227,60$ \\
\hline \multicolumn{2}{|c|}{ Total } & 943,80 & 943,80 \\
\hline \multicolumn{3}{|c|}{ Descuento por rampa } & $-90,48$ \\
\hline \multicolumn{3}{|c|}{ Descuento por torres salvavidas (X3) } & $-48,30$ \\
\hline \multicolumn{3}{|c|}{ Total área efectiva de uso turístico } & $9.789,17$ \\
\hline
\end{tabular}

\begin{tabular}{|c|c|c|c|c|c|}
\hline \multicolumn{6}{|c|}{ Área de Circulación } \\
\hline & $\begin{array}{c}\text { Ancho } \\
\text { Bruto } \\
\text { (m) }\end{array}$ & $\begin{array}{c}\text { Ajuste } \\
\text { por } \\
\text { marea }\end{array}$ & $\begin{array}{c}\text { Ancho } \\
\text { Comercial } \\
(\mathrm{m})\end{array}$ & $\begin{array}{l}\text { Base } \\
(\mathrm{m})\end{array}$ & $\begin{array}{l}\text { Área } \\
\left(\mathrm{m}^{2}\right)\end{array}$ \\
\hline Área 1 & 28,00 & \multirow{8}{*}{$80 \%$} & 7,50 & 99,54 & 746,55 \\
\hline Área 2 & 28,00 & & 7,50 & 99,54 & 746,55 \\
\hline Área 3 & 10,10 & & 7,50 & 121,21 & 909,08 \\
\hline Área 4 & 10,10 & & 7,50 & 68,94 & 517,05 \\
\hline Área 5 & 10,10 & & 7,50 & 13,37 & 850,28 \\
\hline Área 6 & 8,80 & & 7,00 & 86,09 & 606,07 \\
\hline Área 7 & 8,80 & & 7,00 & 157,11 & $1.106,05$ \\
\hline Área 8 & 8,80 & & 7,00 & 198,00 & $1.393,92$ \\
\hline \multicolumn{4}{|c|}{ Total área de circulación } & 943,80 & $6.875,55$ \\
\hline
\end{tabular}

Elaboración: Autores
En cuanto a la playa de Chipipe, la medición fue relativamente más fácil por ser una playa de forma más regular. Sin embargo, se establecieron 4 áreas rectangulares. El procedimiento aplicado para el cálculo de las áreas efectivas fue similar al utilizado en la de San Lorenzo, la extensión efectiva de la playa es de 959 metros. La Tabla 2 muestra los resultados de la medición para la playa de Chipipe.

Tabla 2. Cálculo de áreas fijas y áreas de circulación en la playa de Chipipe

\begin{tabular}{|c|c|c|c|c|c|}
\hline \multicolumn{6}{|c|}{ Área Fija } \\
\hline \multicolumn{2}{|c|}{ Rectángulos } & $\begin{array}{c}\text { Ancho } \\
(\mathrm{m})\end{array}$ & \multicolumn{2}{|c|}{$\begin{array}{r}\text { Base } \\
(\mathrm{m})\end{array}$} & $\begin{array}{l}\text { Área } \\
(\mathrm{m})\end{array}$ \\
\hline \multicolumn{2}{|c|}{ Área 1} & 12,50 & \multicolumn{2}{|c|}{342,48} & $4.281,00$ \\
\hline \multicolumn{2}{|c|}{ Área 2} & 15,90 & \multicolumn{2}{|c|}{160,62} & $2.553,86$ \\
\hline \multicolumn{2}{|c|}{ Área 3} & 22,00 & \multicolumn{2}{|c|}{235,80} & $5.187,60$ \\
\hline \multicolumn{2}{|c|}{ Área 4} & 22,00 & \multicolumn{2}{|c|}{220,34} & $4.847,48$ \\
\hline \multicolumn{3}{|c|}{ Total } & \multicolumn{2}{|c|}{959,24} & $16.869,94$ \\
\hline \multicolumn{5}{|c|}{ Descuento por rampa } & $-256,71$ \\
\hline \multicolumn{5}{|c|}{ Descuento por torres salvavidas (X3) } & $-100,80$ \\
\hline \multicolumn{5}{|c|}{ Total área efectiva de uso turístico } & $16.512,43$ \\
\hline \multicolumn{6}{|c|}{ Área de Circulación } \\
\hline & $\begin{array}{c}\text { Ancho } \\
\text { Bruto } \\
\text { (m) }\end{array}$ & $\begin{array}{c}\text { Ajuste } \\
\text { por } \\
\text { marea }\end{array}$ & $\begin{array}{c}\text { Ancho } \\
\text { Comercial } \\
\text { (m) }\end{array}$ & $\begin{array}{c}\text { Base } \\
(\mathrm{m})\end{array}$ & $\begin{array}{l}\text { Área } \\
\left(m^{2}\right)\end{array}$ \\
\hline Área 1 & 16,90 & \multirow{4}{*}{$80 \%$} & 7,50 & 342,48 & $2.568,60$ \\
\hline Área 2 & 15,10 & & 7,50 & 160,62 & $1.204,65$ \\
\hline Área 3 & 21,00 & & 7,50 & 235,80 & $1.768,50$ \\
\hline Área 4 & 21,00 & & 7,50 & 220,34 & $1.652,55$ \\
\hline \multicolumn{5}{|c|}{ Total área de circulación } & $7.194,30$ \\
\hline
\end{tabular}

Elaboración: Autores

Si se considera que en general hay libre movilidad de vendedores ambulantes entre una playa y otra y que no está claramente delimitada el área de operación de cada Asociación ${ }^{3}$, se procedió a realizar una estimación conjunta de la capacidad de carga de las dos playas. La Tabla 3 resume las superficies estimadas de las áreas efectivas de ambas playas.

Tabla 3. Áreas efectivas de las playas de San Lorenzo y Chipipe

\begin{tabular}{|c|c|c|c|}
\cline { 2 - 4 } Playa & $\begin{array}{c}\text { Total área } \\
\text { efectiva de } \\
\text { uso turístico }\end{array}$ & $\begin{array}{c}\text { Total área } \\
\text { efectiva de } \\
\text { circulación }\end{array}$ & $\begin{array}{c}\text { Total } \\
\mathbf{( m}^{2} \mathbf{~}\end{array}$ \\
\hline San Lorenzo & 9.789 & 6.876 & 16.665 \\
\hline Chipipe & 16.513 & 7.194 & 23.707 \\
\hline Total & $\mathbf{2 6 . 3 0 2}$ & $\mathbf{1 4 . 0 7 0}$ & $\mathbf{4 0 . 3 7 2}$ \\
\hline
\end{tabular}

Elaboración: Autores 
El área relevante para el cálculo de la CCF es el área efectiva de uso turístico, que básicamente corresponde al área donde se instalan las carpas y parasoles yen donde hacen base la mayoría de turistas.

\section{Cáculo de área usada por turistas}

En playas urbanas, el espacio por usuario prescrito es de $5 \mathrm{~m}^{2}$ (Roig, 2003). Este mismo criterio utilizan Hurtado \& Rodríguez (2007) y Reck (2006). Otros autores citados por Reck, consideran un máximo tolerable entre 3 y $5 \mathrm{~m}^{2}$ para el área de mayor saturación de una playa; en efecto, Roig (2003) encontró que algunas playas de la isla de Menorca en España, no superaban los $5 \mathrm{~m}^{2}$ por usuario en el momento de máxima ocupación.

Para estimar el área real que actualmente usa un turista en las playas de estudio, se procedió a realizar un conteo de turistas durante un fin de semana que coincidió con un largo feriado nacional.

Para el efecto, se determinaron 5 bloques muestrales en cada playay en cadabloquese delimitaron dosáreas de $25 \mathrm{~m}^{2}(5 \times 5 \mathrm{~m})$, excepto en uno de los bloques en que se delimitó una sola área de $25 \mathrm{~m}^{2}$ por haber una menor concentración de turistas en ese bloque, es decir las áreas de muestreo fueron seleccionadas por conveniencia en función de la mayor concentración de turistas, con el fin de reflejar en la medida de lo posible un escenario típico de temporada alta. Los resultados obtenidos se muestran en la Tabla 4.

Tabla 4. Cálculo de área usada por turista

\begin{tabular}{|c|c|c|c|}
\hline \multirow{2}{*}{ Bloques } & \multicolumn{3}{|c|}{ San Lorenzo } \\
\cline { 2 - 3 } & $\begin{array}{c}\text { Número de } \\
\text { turistas }\end{array}$ & $\begin{array}{c}\text { Área } \\
\text { observada }\end{array}$ & \multirow{2}{*}{$\mathbf{m}^{\mathbf{2}} /$ turista } \\
\hline A & 16 & 50 & \multirow{1}{*}{} \\
\hline B & 8 & 50 & \multirow{2}{*}{3,57} \\
\hline C & 23 & 50 & \\
\hline D & 9 & 50 & \\
\hline E & 7 & 25 & \\
\hline Totales & $\mathbf{6 3}$ & $\mathbf{2 2 5}$ & \\
\hline
\end{tabular}

\begin{tabular}{|c|c|c|c|}
\hline \multirow{2}{*}{ Bloques } & \multicolumn{3}{|c|}{ Chipipe } \\
\cline { 2 - 3 } & $\begin{array}{c}\text { Número de } \\
\text { turistas }\end{array}$ & $\begin{array}{c}\text { Área } \\
\text { observada }\end{array}$ & \multirow{2}{*}{$\mathbf{m}^{2} /$ turista } \\
\hline A & 33 & 50 & \\
\hline B & 38 & 50 & \multirow{2}{*}{} \\
\hline C & 41 & 50 & \multirow{2}{*}{$\mathbf{4 2}$} \\
\hline D & 25 & 50 & \\
\hline E & 22 & 25 & \multirow{2}{*}{} \\
\hline Totales & $\mathbf{1 5 9}$ & $\mathbf{2 2 5}$ \\
\hline \hline \multicolumn{2}{|c|}{ Promedio $\mathrm{m}^{2} /$ turista } \\
\hline
\end{tabular}

Elaboración: Autores
Al momento de realizar el conteo, la playa de Chipipe mostraba una mayor densidad de turistas que San Lorenzo. De acuerdo con las observaciones realizadas en el momento se pudo determinar que mientras en Chipipe la gente permanecía concentrada más en las carpas y parasoles, no era el caso de San Lorenzo en que la gente estaba más dispersa y muchos estaban en el agua.

En todo caso, la mayor densidad observada en Chipipe es una aproximación bastante real de lo que ocurre durante una temporada alta, mientras que el promedio de las dos áreas, sería una aproximación adecuada para una temporada normal. En cualquier caso, estos datos estarían por debajo de lo máximo tolerable citado por Reck (2006) pero tendría consistencia con lo encontrado por Roig (2003) en algunas playas donde esta densidad no superaba los $5 \mathrm{~m}^{2}$. Si se considera que $5 \mathrm{~m}^{2}$ es lo prescrito para una playa urbana para que los turistas tengan una experiencia cómoda y placentera, la realidad muestra que en temporada alta y aún durante fines de semana fuera de temporada, estas playas tienden a sobresaturarse y por lo tanto a hacer menos placentera la experiencia de los turistas.

\section{Cálculo del área de ocupación de las actividades comerciales}

Paraestoseescogieronal azar dos vendedores por cada actividadcomercialysemidióelárea promedioutilizada. Se estableció un rectángulo comoárea efectivamente ocupada por el vendedor incluyendo el utensilio en el cual transporta la mercancía, puede ser este un carrito, un canasto, una bandeja o cualquier otro según la actividad específica. En la medición se consideró además una distancia de $50 \mathrm{~cm}$ adicionales por lado como margen de movilidad para atención a la clientela y facilidad de movimiento del mismo vendedor.

Una vez, calculadas las áreas que individualmente ocupa cada actividad, se multiplicó por el número de actividades de cada categoría para obtener así el área efectiva total utilizada por los vendedores ambulantes. El área total ocupada por los 582 vendedores ambulantes fue de $1.703 \mathrm{~m}^{2}$, es decir en promedio cada vendedor ocupa un área de 2,95 $\mathrm{m}^{2}$ para ejercer cómodamente su actividad.

\section{RESULTADOS Y DISCUSIÓN}

\section{Estimación de la CCF}

Una vez obtenidas las áreas efectivas de uso turístico y el área usada por turista, se procedió a calcular la capacidad de carga física de turistas. A 
base de este resultado y tomando en consideración la relación de un vendedor por cada 10 turistas $(1 / 10)$ establecida por la Ordenanza, se calculó el número de vendedores que pueden atender a la capacidad máxima estimada de turistas.

Sin embargo, esta relación en una temporada alta podría no ser tan real tomando en cuenta la alta concentración de turistas que llegan normalmente ansiosos por recibir atención y consumir productos de todo tipo, situación que induciría a los vendedores a esmerarse más de lo normal para atender a la oleada de turistas y sus persistentes demandas, de manera que no sería tan irreal asumir que en tales condiciones la relación podría ser un vendedor por cada 25 turistas $(1 / 25)^{4}$. Tomando en cuenta este aspecto, se establecieron 4 escenarios para el cálculo de la CCF:

Escenario 1: temporada alta con Ordenanzaactual Escenario 2: temporada normal con Ordenanza actual

Escenario 3: temporada alta con Ordenanza modificada

Escenario 4: temporada normal con Ordenanza modificada

Los escenarios 3 y 4 utilizan la relación $1 / 25$, lo cual requeriría una modificación en la Ordenanza vigente. La Tabla 6 muestra los resultados obtenidos.

Tabla 5. Capacidad de carga física de turistas y número correspondiente de vendedores ambulantes en las dos playas San Lorenzo y Chipipe

\begin{tabular}{|c|c|c|c|c|}
\hline Escenario & $\begin{array}{c}\text { Área efectiva de } \\
\text { uso turístico } \\
\left(\mathbf{m}^{2}\right)\end{array}$ & $\begin{array}{c}\text { Área utilizada } \\
\text { por turista } \\
\left(\mathbf{m}^{2}\right)\end{array}$ & $\begin{array}{c}\text { Capacidad de carga física } \\
\text { (Número de turistas) }\end{array}$ & $\begin{array}{c}\text { Capacidad de carga de } \\
\text { vendedores ambulantes } \\
\text { (Números de vendedores) }\end{array}$ \\
\hline 1 & 26.302 & 1,42 & 18.522 & 1.852 \\
\hline 2 & 26.302 & 2,49 & 10.563 & 1.056 \\
\hline 3 & 26.302 & 1,42 & 18.522 & 741 \\
\hline 4 & 26.302 & 2,49 & 10.563 & 423 \\
\hline
\end{tabular}

Elaboración: Autores

Estos resultados indicarían que en un feriado o fin de semana de temporada alta, las playas de San Lorenzo y Chipipe pueden recibir hasta 18.500 personas, mientras que en temporada normal hasta 10.500. Aunque no existen investigaciones que midan con precisión la afluencia de turistas específicamente a estas playas, como parte de este estudio se realizó un estimativo a base de datos obtenidos de Palacios (2015) y al número de espacios de parqueos disponibles, llegándose a determinar que aproximadamente 22.000 personas llegan a Salinas en un feriado de temporada alta, lo cual es coherente con las estimaciones de carga realizadas.

Además, se puede ver que la capacidad de carga de vendedores ambulantes es altamente sensible al ratio vendedor-turistas, de manera que esta relación debe ser objeto de mayor investigación y análisis.

Tabla 6. Estimación de número de vendedores ambulantes y áreas adicionales requeridas

\begin{tabular}{|c|c|c|c|c|c|c|}
\hline \multirow{2}{*}{ Escenario } & \multirow{2}{*}{$\begin{array}{c}\text { Número de } \\
\text { vendedores } \\
\text { según estudio }\end{array}$} & \multirow{2}{*}{$\begin{array}{c}\text { Número } \\
\text { actual de } \\
\text { vendedores }\end{array}$} & \multicolumn{2}{|c|}{$\begin{array}{l}\text { Vendedores } \\
\text { adicionales }\end{array}$} & \multirow{2}{*}{$\begin{array}{l}\text { Área de } \\
\text { ocupación } \\
\text { por }\left(m^{2}\right)\end{array}$} & \multirow{2}{*}{$\begin{array}{c}\text { Área de adicional que } \\
\text { ocuparían los } \\
\text { vendedores } \\
\text { adicionales }\end{array}$} \\
\hline & & & Número & $\begin{array}{c}\text { Variación } \\
\%\end{array}$ & & \\
\hline 1 & 1.852 & 582 & 1.270 & $+218 \%$ & 2,95 & 3,743 \\
\hline 2 & 1.056 & 582 & 474 & $+81 \%$ & 2,95 & 1,397 \\
\hline 3 & 741 & 582 & 159 & $+27 \%$ & 2,95 & 468 \\
\hline 4 & 423 & 582 & -159 & $-27 \%$ & 2,95 & -470 \\
\hline
\end{tabular}

Elaboración: Equipo de investigación de la UTE

\section{Comparación con el número actual de vendedores ambulantes}

El número de vendedores estimado a partir de la capacidad de carga turística es un 
indicador del número "ideal" de vendedores ambulantes que deberían estar disponibles en las playas según los escenarios presentados.

La Tabla 6 presenta un comparativo de este número de vendedores proyectados en cada escenario con el número actual de vendedores ambulantes registrados y operativos.

Se puede apreciar que en todos los escenarios habría necesidad de contar con mayor número de comerciantes ambulantes, excepto en el escenario 4 , donde tendría que reducirse la cantidad actual de vendedores en un $27 \%$. El escenario 1 es el que necesitaría la mayor cantidadadicional de vendedores, con un incremento del $218 \%$ sobre el número actual.

En términos deáreaadicional de ocupación, utilizando la densidad actual de ocupación por vendedor, estimada en $2,95 \mathrm{~m}^{2}$, se observa que el escenario 1 requeriría la mayor área adicional, esto es $3.743 \mathrm{~m}^{2}$. Si se toma en cuenta que existe un área efectiva de circulación de $14.070 \mathrm{~m}^{2}$ en las dos playas, que es pordonde preferentemente circulan los vendedores ambulantes, esto implicaría que se estaría ocupando hasta un 26,6\% adicional del área de circulación en caso de darse las condiciones del escenario 1. Sin embargo, esto no afectaría mayormente la comodidad de los turistas, puesto que siempre habrá menor número de turistas en un momento dado en esta área que con respecto al área de carpas y parasoles.

\section{CONCLUSIONES}

Este estudio estimó un área comercial fija en ambas playas de $26.302 \mathrm{~m}^{2}$ así como también un área de ocupación por turista $\left(1,42 \mathrm{~m}^{2}\right.$ en temporada alta y $2,49 \mathrm{~m}^{2}$ en temporada normal) y por vendedor $\left(2,95 \mathrm{~m}^{2}\right)$, datos que sirvieron para estimar las capacidades de carga física tanto de turistas como de vendedores, así como algunos indicadores de relación con el número actual de vendedores ambulantes. Estos datos a su vez permitieron reflejar el número de vendedores potenciales que podrían sumarse a los existentes para responder a la demanda de turistas en época de temporada alta y normal, tomando como referencia la Ordenanza vigente, que establece la relación un vendedor por cada 10 turistas.

Seplantearon cuatroescenariosalternando temporada alta y normal con la normativa vigente y propuesta. En los dos primeros escenarios se obtuvo una capacidad de carga física de 18.522 y 10.563 turistas en ambas playas; el escenario 1 utilizó la densidad de $1,42 \mathrm{~m}^{2}$ por turista en temporada alta y el escenario 2 la de $2,49 \mathrm{~m}^{2}$ por turista en temporada normal. La proyección correspondiente de vendedores fue de 1.852 y 1.056 mediante la relación $1 / 10$ de la Ordenanza, esto implicaría 1.270 y 474 vendedores adicionales a los actuales.

Para los dos escenarios adicionales, se tomó en consideración una posible reforma a la Ordenanza, con una relación 1/25. Con este antecedente, en el escenario 3 con la misma cantidad de turistas proyectada en el escenario 1 serían necesarios 741 vendedores mientras que en el escenario 4 con la misma cantidad de turistas proyectada en el escenario 2 serían necesarios 423 vendedores, es decir que en temporada alta se requerirían 159 vendedores adicionales mientras que en época normal podría reducirse la cantidad de vendedores en 159 .

En las observaciones de campo realizadas, se visualizaron comerciantes ambulantes de empresas privadas de helados y refrescos en un alto número que vendían sus productos en ambas playas. Según la autoridad competente, estos vendedores tienen autorización para vender en las playas. De ser así, parte de las necesidades adicionales de vendedores ambulantes en los escenarios presentados serían suplidas por los comerciantes de marcas autorizadas, los mismos que no fueron considerados en los cálculos por no tener disponible información oficial sobre el número de permisos concedidos a estos vendedores.

\section{REFERENCIAS BIBLIOGRÁFICAS}

Antón, S., González, F., Andreu, N., Donaire, J., Galacho, B., García, M., López, D., Mateu,J. \& Puertas, J. (2005). Planificación territorial del turismo. Editorial UOC, Barcelona, España. Disponible en: https://books.google.com/books?isbn $=8497883527$

Cifuentes, M. (1992). Determinación de capacidad de carga turística en áreas protegidas. Centro Agronómico Tropical de Investigación y Enseñanza - CATIE, Costa Rica.

Dias,I.,Korossy,N.\& Fragoso,V. (2012). Determinación de la capacidad de carga turística. El caso de Playa de Tamandaré - Pernambuco - Brasil. Estudios y Perspectivas en Turismo 21(2012): 1630 - 1645.

Fioravanti, M., Parducci, M., Reátegui, K., Troya, U. \& Vega, N. (2007). Normas Técnicas para el establecimiento de un programa de certificación de playas turísticas en la faja costera (Estudio bajo contrato del Programa de Manejo de Recursos Costeros - PMRC y Subsecretaría de Turismo 
del Litoral). Ecosambito Cía. Ltda. Guayaquil.

Gobierno Autónomo Descentralizado del Cantón Salinas (2011). Plan de Desarrollo y Ordenamiento Territorial del Cantón Salinas 2011 - 2016.

Gobierno Autónomo Descentralizado del Cantón Salinas (2013). Ordenanza regulatoria de las actividades productivas y manejo integral de las playas de San Lorenzo, Chipipe, La Milina, Puerto Lucía, Punta Carnero del cantón Salinas de la provincia de Santa Elena.

Hurtado, L. \& Rodríguez, M. (2007). Estudio de capacidad de carga de la playa Punta Carnero del cantón Salinas y propuestas para mejorar su desarrollo turístico (Tesis de Grado). Escuela Superior Politécnica del Litoral. Guayaquil.

Ministerio del Ambiente (2009). Zonificación y Ordenamiento Territorial en la zona de playa y babía en la franja costera del Ecuador. Informe final del estudio bajo contrato del Programa de Manejo de Recursos Costeros - PMRC. Ecosambito Cía. Ltda. Guayaquil

Ministerio de Turismo del Ecuador (2015). Boletín de Estadísticas Turísticas 2010-2014. Quito. Disponible en: http://servicios.turismo.gob.ec/descargas/ Turismo-cifras/BoletinesEstadisticos/Anuario/ Boletin-Estadisticas-Turisticas-2010-2014.pdf

Navarro Jurado, E. (2005). ¿Puede seguir creciendo la Costa del Sol? Capítulo III: El concepto de capacidad de carga: marco básico para la propuesta de indicadores de saturación. Disponible en: http://www. indicasig.uma.es/Resources/Capitulo\%203.pdf)

Novaes, V., Silva, L. \& de Oliveira, W. (2010). La economía en las playas de Sergipe (Brasil). Estudiosy Perspectivas en Turismo 19(2010): 63-82.

Palacios, J. (2015). Variables explicativas de la demanda y de la oferta del turismo en la provincia de Santa Elena. Tesis de Maestría no publicada. Escuela Superior Politécnica del Litoral, Guayaquil.

Reck, G. (2006). Estudio de la Oferta y demanda turística y carga aceptable de acuerdo a limitaciones actuales y escenarios de desarrollo de infraestructura y servicios de 17 playas de las provincias de Esmeraldas, Manabi, Guayasy ElOro (Estudio bajo contrato del PMRC). Quito, agosto 2006.

Roig, F. (2003). Análisis de la relación entre capacidad de carga física y capacidad de carga perceptual en playas naturales de la isla de Menorca. Investigaciones Geográficas 31(2003): 107-118.

Ruschmann, D., Paolucci, L. \& Maciel, N. (2008). Capacidade de carga no planejamento turístico: estudo de caso da Praia Brava - Itajaí frente à implantação do Complexo Turístico Habitacional Canto da Brava. RevistaBrasileira de Pesquisa em Turismo 2(2): 41-63.

Wagar, J.A. (1964). The Carrying Capacity of Wild Lands for Recreation. Forest Science Monograph 7. Society of American Foresters,

Washington D.C. Disponible en: http://personal. crocodoc.com $/ 0$ r9hJVb? embedded = true

\section{Notas}

${ }^{1}$ Esta sección es extraída principalmente del Plan de Desarrollo y Ordenamiento Territorial del Cantón Salinas 2011 - 2016 (GADSA 2011).

${ }^{2}$ Esta realidad fue expuesta por los mismos socios en reuniones mantenidas durante el desarrollo del estudio.

${ }^{3}$ A decir de algunos socios, no existen en sí zonas ni playas exclusivas para la operación de una determinada Asociación, en muchos casos se superponen las actividades de diferentes asociaciones pero esto no genera conflictos entre ellas. Los conflictos son por lo general con los no asociados o vendedores informales.

${ }^{4}$ Una estimación de esta relación vendedor-turista más ceñida a lo real sería objeto de otro estudio que escapa al actual, pues implicaría un análisis más a fondo de la demanda de los turistas plaveros.

5 No obstante lo anotado, un escenario como el 1 e incluso el 2, sí tendrían potencialmente un impacto negativo sobre el "confort" del turista al disponer de menos area para la práctica de actividades recreativas y deportivas en la arena húmeda y particularmente en el área de circulación. 